•综述・

\title{
土壤动物群落空间格局和构建机制研究进展
}

\author{
高梅香 ${ }^{1,2}$ 林 琳 ${ }^{1,2}$ 常 亮 ${ }^{3}$ 孙新 ${ }^{3}$ 刘 冬 $^{3}$ 吴东辉, $34^{*}$ \\ 1 (哈尔滨师范大学地理科学学院, 哈尔滨 150025) \\ 2 (哈尔滨师范大学寒区地理环境监测与空间信息服务黑龙江省重点实验室, 哈尔滨 150025) \\ 3 (中国科学院东北地理与农业生态研究所湿地生态与环境重点实验室, 长春 130102) \\ 4 (东北师范大学植被科学教育部重点实验室, 长春 130024)
}

摘要: 群落空间格局和构建机制一直是生态学研究的核心内容。在生物多样性严重丧失的背景下, 揭示群落空间 格局及其构建机制, 有助于深刻理解生物多样性丧失的原因, 更有助于应对生物多样性保护等重大生态环境问 题。然而, 陆地生态系统的研究多集中于地上生物群落, 对地下生态系统, 尤其是土壤动物空间格局和构建机制的 研究尚不充分。事实上, 土壤动物多样性是全球生物多样性的关键组成之一, 是地下生态系统结构和功能维持的 重要部分。对土壤动物空间格局和构建机制的研究, 能明确不同空间尺度条件下土壤动物多样性的维持机制。土 壤动物群落常在多种空间尺度形成复杂的空间分布格局, 因此, 本文首先介绍了不同空间尺度主要土壤动物群落 的空间自相关性特征, 阐述了土壤动物群落斑块和孔隙镶嵌分布的复杂空间格局。继而阐明这种空间格局主要受 生物间作用、环境过滤和随机扩散的调控, 并说明这三个过程对土壤动物群落的调控能力和作用方式。作者提出, 这三个过程仍是今后土壤动物群落空间格局和构建机制研究的重点内容, 需要进一步加强以土壤动物为研究对象 的群落构建理论的验证和发展。我国土壤动物群落空间格局和构建机制起步较晚, 希望本文能够促进我国土壤动 物生态学相关领域的研究。

关键词：空间尺度；空间异质性；多样性维持；生物间作用；环境过滤；随机扩散

\section{Spatial patterns and assembly rules in soil fauna communities: A review}

\author{
Meixiang Gao ${ }^{1,2}$, Lin Lin ${ }^{1,2}$, Liang Chang ${ }^{3}$, Xin Sun ${ }^{3}$, Dong $\mathrm{Liu}^{3}$, Donghui $\mathrm{Wu}^{3,4^{*}}$ \\ 1 College of Geographical Sciences, Harbin Normal University, Harbin 150025 \\ 2 Heilongjiang Province Key Laboratory of Geographical Environment Monitoring and Spatial Information Service in \\ Cold Regions, Harbin Normal University, Harbin 150025 \\ 3 Key Laboratory of Wetland Ecology and Environment, Northeast Institute of Geography and Agroecology, Chinese \\ Academy of Scieneces, Changchun 130102 \\ 4 Key Laboratory of Vegetation Ecology of Ministry of Education, Northeast Normal University, Changchun 130024
}

\begin{abstract}
Identifying spatial patterns and assembly rules in communities is a central study topic in ecology. With the unprecedented rate at which biodiversity is decreasing, it is necessary to recognize the spatial patterns and assembly rules in communities in order to understand why biodiversity is being lost and to be able to protect it. However, previous studies have focused more on plant communities in above-ground terrestrial ecosystems, neglecting below-ground ecosystems, especially soil faunal communities. Indeed, soil faunal biodiversity is a crucial component of global biodiversity because soil faunal communities assist in the maintenance of important ecosystem structures and functions. Therefore, one important aim of identifying spatial patterns and assembly rules in soil faunal communities is to clarify mechanisms of maintaining soil faunal biodiversity at multiple scales, so as to promote these processes, which also maintain ecosystem structures and functions. Soil faunal communities usually form complicated spatial patterns at multiple spatial scales. Here, we propose spatial autocorrelation characteristics, and then show how the complicated spatial patterns are demonstrated by patches and gaps of soil faunal communities at multiple scales. These spatial patterns are mainly controlled by processes of biotic interactions, environmental filtering and random
\end{abstract}

收稿日期: 2018-04-16; 接受日期: 2018-07-03

基金项目: 国家自然科学基金(41471037, 41430857)和哈尔滨师范大学优秀青年基金(XKYQ201401)

* 通讯作者 Author for correspondence. E-mail: wudonghui@neigae.ac.cn 
dispersal. Consequently, we discuss the impacts of these processes on soil faunal communities. Finally, we suggest that these three processes are essential to evaluate and construct a theoretical framework for soil faunal communities and should continue to be studied in the future. Because interest in spatial patterns and assembly rules of soil faunal communities is relatively new in China, we expect this review will promote the development of related research areas.

Key words: spatial scale; spatial heterogeneity; biodiversity maintainance; biotic interaction; environmental filtering; random dispersal

群落格局和构建机制(维持机制)一直是群落生 态学和生物地理学的核心问题(Huston, 1994; 牛克 昌等, 2009), 其中最关键的是物种共存机制, 生态 位理论和中性理论围绕这一问题展开了激烈的争 论。生态位理论强调确定性因素是主导过程, 认为 群落物种共存以生态位分化为前提, 有相同生态位 的物种因为对共同资源的喜好产生激烈竞争, 这种 竞争排斥作用致使物种不能稳定共存(Diamond, 1975)。然而传统的生态位理论在解释婆罗洲热带雨 林物种多样性时遇到了挑战(Bell, 2000; Hubbell, 2001), 相关研究认为该生境内无明显限制性资源、 无明显多物种生态位分化, 群落内物种却依然稳定 共存。在此背景下中性理论开始备受关注, 该理论 认为相似物种可以共存, 强调扩散和随机作用是群 落构建的主导过程(Hubbell, 2001)。然而生态位理论 和中性理论并非对立, 二者共同解释土壤动物群落 的构建, 只是在不同空间尺度下其作用强度不同 (Gao et al, 2014)。研究表明土壤动物群落主要受三 个过程的调控, 即扩散 (dispersal)、环境过滤 (environmental filtering)和生物间作用(biotic interaction), 它们在多尺度上调控群落物种共存和维持生 物多样性(Leibold et al, 2004; Emerson \& Gillespie, 2008)。量化这三个过程的相对作用强度, 是确定生 态位理论和中性理论相对贡献的基本途径, 也是群 落生态学揭示地下群落构建机制的主要途径(Bell, 2010; Caruso et al, 2011)。

土壤动物物种多样、数量丰富、分布广泛, 参 与物质分解、营养供应等生态学过程并为人类提供 关键的生态系统服务(Ettema \& Wardle, 2002; Lavelle et al, 2006)。尽管土壤动物多样性是全球生物多 样性最关键的组成之一, 但目前相关研究主要集中 于地上植被和动物群落(Ettema \& Wardle, 2002; Whittaker \& Heegaard, 2003), 对土壤动物群落空间 格局和构建机制研究明显不足(Bardgett, 2002), 这
阻碍了地下生态系统多样性维持机制研究。本文首 先综述了土壤动物群落多尺度空间格局, 通过阐明 生物间作用、环境过滤和随机扩散对土壤动物群落 构建的相对重要性, 说明生态位理论和中性理论对 土壤动物群落维持的相对解释能力, 总结和展望其 发展趋势和研究重点。通过综述土壤动物群落空间 格局和构建机制这一群落生态学的核心问题(Heike et al, 2009; Lindo \& Winchester, 2009; Decaëns, 2010; Berg, 2012; Caruso et al, 2012), 以期促进我国土壤 动物群落空间格局和构建机制研究。

\section{土壤动物群落空间格局和构建机制的尺}

土壤动物群落空间格局和构建机制具尺度效 应(Borcard \& Legendre, 2002; Ettema \& Wardle, 2002), 即在不同的空间尺度条件下其群落格局和 构建机制不同(Chase \& Leibold, 2002), 且一个群落 可能同时受到来自多个尺度过程的调控(Levin, 1992), 所以量化空间尺度是理解群落空间格局和 构建机制的关键 (Cadotte \& Fukami，2005; Gascoigne et al, 2005)。空间尺度参数包括空间幅度、 空间粒度和聚焦尺度(Lundholm, 2009)。空间幅度是 样方所在的全部面积大小; 空间粒度是异质性测量 的尺度, 即斑块大小, 一般认为是邻近测量样点的 平均空间距离; 聚焦尺度是测量物种多样性的尺度, 例如采集土壤动物的样方大小。其中空间幅度受到 了较多关注, 尽管空间幅度从研究样地到整个大陆 是连续变化的, 但为了研究方便常划分为离散尺度, 例如小尺度、局地尺度、区域尺度和全球尺度 (Leibold et al, 2004)。在群落物种构建机制研究中, 空间粒度比其他尺度参数更重要, 因为物种是对环 境距离斑块响应而不是对抽象的异质性指标响应 (Tamme et al, 2010)。引起异质性的原因也可能因尺 度而异(Ettema \& Wardle, 2002), 在不同的空间尺度 
条件下，构建机制对群落的调控作用又因环境条件 而异(Bardgett et al, 2005), 这使群落格局和构建机 制的研究更加复杂。本文主要关注不同空间幅度内 土壤动物群落空间格局和构建机制, 分别关注小尺 度、局域尺度和区域尺度的研究现状。

\section{2 土壤动物群落空间格局}

由于计算机技术的发展, 空间直观方法(spatially explicit methods)在生态学中的应用越来越广 泛(DeAngelis \& Yurek, 2017), 该方法结合生态学和 空间数据, 可以在空间维度直观地展示、评估、模 拟和预测生态学格局和过程(Sala et al, 2010), 尤其 是那些具有空间依赖性的生态学过程(DeAngelis \& Yurek, 2017)。基于空间直观方法有助于揭示土壤动 物群落多尺度空间格局(Beale et al, 2010; Blanchet et al, 2013; Jiménez et al, 2014)和群落构建机制理论, 包括源-汇理论(Source-sink Theory)、物种共存的空 间它存效应(Storage Effect)、生物多样性的中性理 论、物种丰富度的竞争-拓殖权衡假说(Competitioncolonization Trade-off) (DeAngelis \& Yurek, 2017) 等。本文着重介绍基于空间直观方法的土壤动物群 落水平空间格局研究进展。基于空间直观方法的土 壤动物格局研究开展较晚(Ettema \& Wardle, 2002)。 尽管研究表明空间格局可以在多种尺度进行预测, 但是土壤动物群落的异质性常常被认为是“噪音”, 使人难以辨别土壤动物群落驱动哪些生态过程, 以 及哪些变量和过程调控土壤动物群落 (Smith \& Wallace, 1976)。因此，长期以来空间异质性被认为 是理解土壤动物群落构建机制和阐明其生态系统 功能的阻碍。现在则普遍认为空间异质性不仅不是 障碍, 反而是理解土壤动物群落格局和构建机制的 关键(Smith \& Wallace, 1976)。

\section{1 空间自相关性}

空间自相关性被称为地理学第一定律(Tobler, 1970), 即空间邻近的群落比空间远离的群落有更 大的相似性。空间自相关性是生态学和地理学数据 最常见的现象 (Legendre, 1993; Kissling \& Carl, 2008), 该现象的存在意味着土壤动物群落分布具 有内在的结构性, 这是土壤动物群落特定空间格局 形成的重要基础。大部分土壤动物群落具有显著的 空间自相关性(Gutiérrez-López et al, 2010), 在小于
$100 \mathrm{~m}$ 的尺度内很少有空间独立性 (Robertson, 1987)。土壤动物群落的空间自相关性依类群和生境 而异，如虾蚓、跳虫、螨类和甲虫等主要土壤动物， 在不同生态系统均具有不同的空间自相关性特征 (表1)。不同土壤动物类群体型大小各异, 其空间自 相关性距离也不尽相同: 通常体型较大的土壤动物 会出现较大的空间自相关性距离(Ettema et al, 2000; Decaëns \& Rossi, 2001)。但尚没有研究明确提出不 同体型土壤动物具有明显不同的空间自相关性特 征，因为除了体型大小之外，土壤动物的空间自相 关性距离还取决于具体的实验设计，例如空间幅 度、空间粒度。如研究发现马德里附近一个森林生 态系统中，蚟蚓、跳虫和螨类具有不同的空间自相 关性距离, 但这些不同体型土壤动物的空间自相关 距离并没有显著差异(Gutiérrez- López et al, 2010)。

\section{表1 主要土壤动物群落的空间自相关性距离}

Table 1 Spatial autocorrelation distances of main soil animal communities

\begin{tabular}{|c|c|c|c|c|}
\hline $\begin{array}{l}\text { 群落 } \\
\text { Community }\end{array}$ & $\begin{array}{l}\text { 生境 } \\
\text { Habitat }\end{array}$ & $\begin{array}{l}\text { 空间幅度 } \\
\text { Spatial } \\
\text { extent } \\
\left(\mathrm{m}^{2}\right)\end{array}$ & $\begin{array}{l}\text { 空间自相 } \\
\text { 关距离 } \\
\text { Range }\left(\mathrm{A}_{0} \text {, }\right. \\
\mathrm{m})\end{array}$ & $\begin{array}{l}\text { 参考文献 } \\
\text { Reference }\end{array}$ \\
\hline \multirow{3}{*}{$\begin{array}{l}\text { 土壤蚯蚓 } \\
\text { Earthworm }\end{array}$} & 草地 & - & $1-50$ & Decaëns et al, 2009 \\
\hline & Grassland & & & \\
\hline & $\begin{array}{l}\text { 森林 } \\
\text { Forest }\end{array}$ & 10,000 & $17-50$ & $\begin{array}{l}\text { Gutiérrez-López } \\
\text { et al, } 2010\end{array}$ \\
\hline \multirow{2}{*}{$\begin{array}{l}\text { 土壤跳虫 } \\
\text { Soil collem- } \\
\text { bola }\end{array}$} & $\begin{array}{l}\text { 森林 } \\
\text { Forest }\end{array}$ & 10,000 & $20-27$ & $\begin{array}{l}\text { Gutiérrez-López } \\
\text { et al, } 2010\end{array}$ \\
\hline & $\begin{array}{l}\text { 农田 } \\
\text { Cropland }\end{array}$ & 250 & $5-50$ & 高梅香等, 2014c \\
\hline \multirow[t]{3}{*}{$\begin{array}{l}\text { 土壤螨类 } \\
\text { Soil mite }\end{array}$} & $\begin{array}{l}\text { 森林 } \\
\text { Forest }\end{array}$ & 25 & $0.5-5$ & 高梅香等, 2014a \\
\hline & & 10,000 & $17-30$ & $\begin{array}{l}\text { Gutiérrez-López } \\
\text { et al, } 2010\end{array}$ \\
\hline & $\begin{array}{l}\text { 农田 } \\
\text { Cropland }\end{array}$ & 250 & $5-40$ & 高梅香等, 2014b \\
\hline \multirow[t]{2}{*}{$\begin{array}{l}\text { 土壤线虫 } \\
\text { Soil nematode }\end{array}$} & $\begin{array}{l}\text { 草地 } \\
\text { Grassland }\end{array}$ & 1,500 & $4-60$ & $\begin{array}{l}\text { Rossi \& Quénéhervé, } \\
1998\end{array}$ \\
\hline & $\begin{array}{l}\text { 农田 } \\
\text { Cropland }\end{array}$ & 1,200 & 9-91 & Liang et al, 2005 \\
\hline \multirow[t]{4}{*}{$\begin{array}{l}\text { 地表甲虫 } \\
\text { Ground beetle }\end{array}$} & $\begin{array}{l}\text { 森林 } \\
\text { Forest }\end{array}$ & 25 & $1-2.5$ & 胡媛媛等, 2018 \\
\hline & & 400 & $5-10$ & 朱纪元等, 2017 \\
\hline & & 900 & $150-450$ & 倪娟平等, 2018b \\
\hline & $\begin{array}{l}\text { 农田 } \\
\text { Cropland }\end{array}$ & 1,600 & 40-150 & 刘洁等, 2017 \\
\hline
\end{tabular}


因为较大空间尺度的研究需要大量的空间采样点 数据, 因此目前土壤动物群落空间自相关性研究多 集中于较小的空间幅度。但这并不说明土壤动物群 落在较大空间幅度没有空间自相关性，相关问题还 有待进一步探讨。

土壤动物群落的空间自相关性可以由内因性 过程引起(即固有空间自相关性) (Fortin \& Dale, 2005), 包括与距离相关的繁殖、扩散、物种形成、 灭绝和地理范围扩展(Legendre, 1993; Diniz et al, 2003); 也可以由外因性过程引起(即诱导空间依赖 性) (Fortin \& Dale, 2005), 包括地貌过程、风、能量 输入和气候限制等空间结构环境因子。空间邻近的 群落一般构建于更相似的环境条件, 这些相似的环 境因子能够导致物种种群形成某种空间结构 (Legendre, 1993; Diniz et al, 2003)。例如Lamto热带 生态站(Station d'Ecologie Tropicale de Lamto)的 2 个 蚯蚓种群(Chuniodrilus zielae和Sthulmania porifera) (Rossi，2003a)的空间自相关性很相似，它们的空间 分布至少部分取决于相同的生态因子, 或者由那些 在多种空间尺度起作用的不同生态因子调控。但即 使在微空间尺度，两个空间邻近但环境并不相似的 地点，其群落结构也会不同(Caruso et al, 2012)。

\section{2 空间格局}

土壤动物常形成高密度(即斑块)和低密度(即 孔隙)镶嵌分布的异质性空间格局(Perry et al, 1999), 这里的斑块定义为局地物种密度显著高于平均密 度, 孔隙定义为局地物种密度显著低于平均密度 (Rossi, 2003a)。在小空间尺度, 土壤动物群落的特 定物种关系会形成斑块性空间格局，这些空间格局 的空间范围取决于土壤动物的体型大小、生态系统 类型和研究采样的空间设计 (Ettema \& Wardle, 2002)。尽管这些空间格局有镶嵌性和复杂性, 当实 验数据充足的时候也可能发现一些普遍性特征。例 如, 不同类群的土壤动物常形成不同大小的集群, 线虫(Ettema et al, 2000)和线蚓(Lavelle \& Spain, 2001)常形成几厘米的集群, 虾蚂常形成几米、几十 米的集群(Decaens \& Rossi, 2001; Margerie et al, 2001; Rossi, 2003b; Decaëns et al, 2009)。而蚂蚁巢 穴的空间集群并不明显, 形成过度分散的格局 (Traniello \& Levings, 1986)。

群落内单个物种种群也可以形成聚集型空间 分布格局。如两种内栖蛏蚓 (Glossodrilus sp. 和
Andiodrilum sp.)随时间呈现出稳定的集群格局，该 格局可能由这些物种的种群繁殖率和生活史性状 引起(Jiménez et al, 2006)。这些虹蚓的高种群繁殖率 使它们快速增长，它们的内栖行为和中等体型意味 着较低的扩散能力, 因此两个物种有可能呈现出显 著的聚集型分布(Jiménez et al, 2006)。体型较小的蚯 蚂(Aymara sp.和Ocnerodrilidae sp.)也呈现出聚集型 的空间分布格局，这些物种多聚集于有机质含量高 的区域，如牛粪、粪堆和甲虫巢穴(Jiménez et al, 1998; Decaëns, 2000), 这些物种的空间分布反映了 营养资源可获得性对空间格局形成的重要性(Jiménez et al, 2006)。

物种-面积关系是土壤动物群落空间格局的重 要基础, 对于一个给定的类群, 其物种丰富度随空 间尺度的增加而增加(MacArthur \& Wilson，1967; Gaston, 2000), 调控该物种-面积关系的机制随尺度 明显变化。在小尺度空间, 随着面积的增加, 调查 到稀有物种的可能性随之增大, 结果可以调查到更 多的物种。在较大的空间尺度，增加的面积可能导 致高的生物多样性和环境稳定性，因此显示较高的 迁入和局地灭亡比例。土壤动物群落的物种-面积 关系报道较少，见于马来群岛的蚂蚁(Wilson, 1961)、 岛屿和大陆的螨类(Maraun et al, 2007)、跳虫 (Ulrich \& Fiera, 2009)和欧洲蚟蚓等(Judas, 1988)。如在一个 给定的面积内, 岛屿上蚂蚁的物种丰富度少于大陆 (Wilson, 1961), 这显示了生境隔离对群落物种丰富 度的负效应。

我国土壤动物群落空间格局研究主要在森林 和农田开展，空间幅度涉及5、20、40、50、300和 $400 \mathrm{~m}$ ，空间粒度涉及 $0.5 、 2 、 5 、 20 、 40$ 和 $50 \mathrm{~m}$ ，分 别以土壤线虫(Liang et al, 2005; 梁文举等, 2006; Hua et al, 2008)、跳虫 (高梅香等, 2014c)、螨类 (高梅 香等, 2014a, b)、步甲、隐翅虫、葬甲(朱纪元等, 2017; 胡媛媛等，2018)和其他地表大型节肢动物(刘洁等, 2017)为对象, 开展了多尺度群落空间格局研究(图 1)。研究表明, 空间自相关性是土壤动物群落的普 遍现象, 土壤动物群落通常在小于 $150 \mathrm{~m}$ 的距离内 呈现显著的空间自相关。土壤动物群落的空间格局 可以用指数、球状、高斯和线性模型进行拟合，其 空间格局多表现为斑块和孔隙镶嵌分布的复杂格 局，这些格局受地形、土壤或植被因子的影响(Hua et al, 2008; 高梅香等, 2015, 2018)。这些空间格局特 


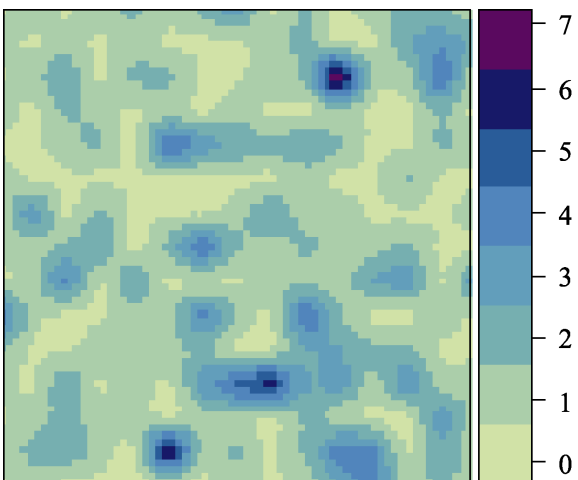

步行虫 Carabid

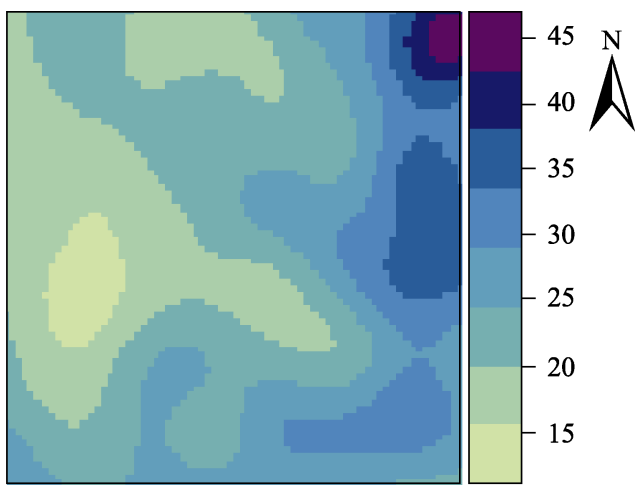

跳虫 Collembola

图1 凉水 9 ha $(300 \mathrm{~m} \times 300 \mathrm{~m})$ 阔叶红松林样地地表步行虫群落(2015年8月)和地下土壤跳虫群落(2014年9月)克里格空间插 值格局图(高梅香等, 2018)

Fig. 1 Kriging prediction maps for ground carabid (August 2015) and soil collembolan (September 2014) communities (Gao et al, 2018)

征依空间尺度和研究类群而异, 且在群落和种群水 平表现规律不同，通常优势物种和常见物种种群的 空间格局特征更明显。

\section{3 土壤动物群落构建机制}

揭示群落构建机制的一个重要途径就是阐明 调控群落格局的典型过程, 这主要包括扩散、环境 异质性和生物间作用。扩散指的是物种沿着生境或 景观从一个地点移动到另一个地点, 扩散决定到达 某个地点的物种集合(Logue et al, 2011; Baguette et $\mathrm{al}, 2013)$ 。环境异质性是一个复杂的概念, 指与环境 相关的空间复杂性、多样性、异质性和结构性的综 合(Stein et al, 2014), 环境异质性决定一个局地群落 是否包含或排除某些物种, 因为它们的功能性状可 能匹配或不匹配局地环境特征。生物间作用既包括 种内作用(intraspecific interaction), 也包括种间作用 (interspecific interaction), 如捕食、寄生、竞争等, 可 以决定物种间的时空分布并产生多种群落结构 (Gascón et al, 2016)。扩散、环境异质性和生物间作 用交互影响, 被认为是一系列的过滤器, 共同决定 群落格局, 因此环境异质性的调控作用也被称为环 境过滤。这三个过程的调控能力依尺度而异: 通常 认为在较大的区域尺度, 受气候条件和地理障碍影 响的扩散过程决定群落格局, 并决定区域物种库对 局域群落物种组成的影响(Dong et al, 2016); 在局 域尺度, 环境过滤可能决定个体的迁入和迁出 (Dong et al, 2016); 而在小尺度, 生物间作用则更加 重要(Gascón et al, 2016) (图2)。需要注意的是，土壤 动物群落格局可能同时受到这三个过程的调控，只
区域群落(区域物种库)

Regional community (regional species pool)

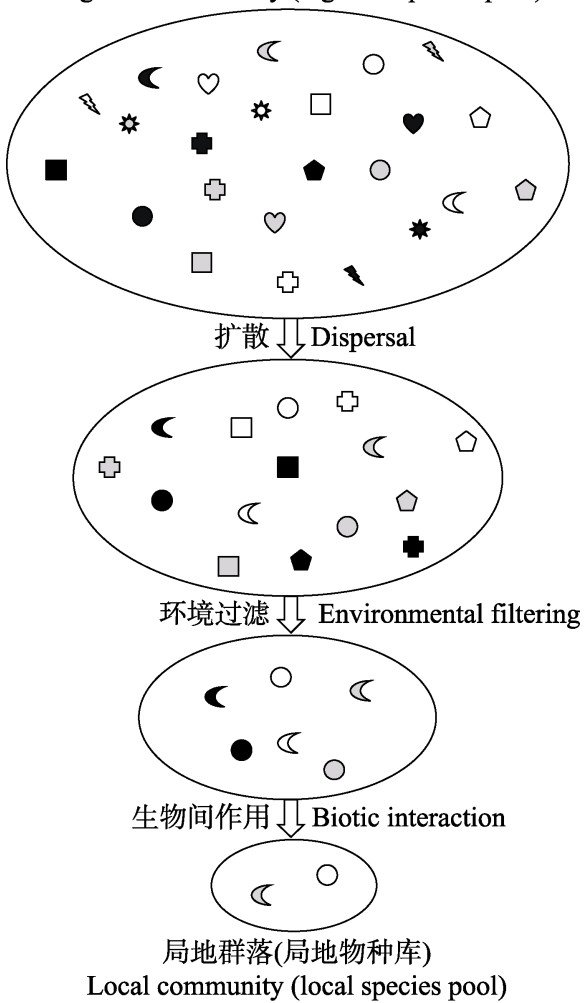

图2 群落构建机制的过滤模型(仿Vellend, 2016)。在这个假 设的案例中, 一个来自区域物种库的随机物种子集进入局 地地点; 只有那些有圆形边缘的物种能够适应局地环境条 件; 竞争淘汰了其他物种, 只留下每个功能类型(以不同形 状表示)的一个物种。由于资源需求不同, 两个剩余物种才能 稳定共存。

Fig. 2 The filter model of community assembly (imitating from Vellend, 2016). In this hypothetical example, a random subset of species in the regional pool has access to a local site; only species with rounded edges can tolerate the environmental conditions; and competition leads to the elimination of all but one species of each functional type (shape). The two remaining species can coexist stably given contrasting resource requirements. 
是在不同空间尺度、对不同土壤动物类群的调控强 度不同(Vellend, 2016)。另外, 任何一种过程对群落 的调控都是依群落特定情况而异(Vellend，2016), 如移除捕食者有时会引起群落格局变化, 有时却对 群落格局并无影响(Shurin et al, 2002)。因此, 研究 不同空间尺度扩散、环境过滤和生物间作用对土壤 动物群落的相对贡献, 对揭示土壤动物群落构建机 制更为重要(Gascón et al, 2016)。

\section{1 生物间作用}

土壤动物多样性受相同营养级内生物间作用 的潜在调控, 尤其是那些受资源影响而不受消费者 影响的群落, 因为这些群落的结构最有可能受到竞 争的调控(de Ruiter et al, 1995; Wardle, 2002)。种内 竞争影响个体表型性状, 例如体型大小和生长速率 (Anderson \& Whiteman, 2015), 这些性状是体现物 种适合度的重要基础(Kingsolver \& Pfennig, 2004; Anderson \& Whiteman, 2015), 进而可能影响群落水 平的一些属性或特征。例如, 种内竞争导致不同大 小越冬幼虫的生长能力差异, 而这种生长能力的差 异可能会强烈地影响群落结构和组成(Anderson et al, 2013; Anderson \& Whiteman, 2015)。但种内竞争 的调控作用在土壤动物群落研究中相对少见, 如种 内竞争调控食物和其他资源, 进而影响蚂蚁巢穴的 空间格局(Traniello \& Levings, 1986)。

局地尺度内相同营养级的种间竞争对土壤动 物群落构建也起重要作用。Diamond (1975)指出种 间竞争会妨碍那些生态学特性相似的物种在群落 内共存。生态位重叠度用来衡量两个或多个物种对 相同资源的利用, 那些在任何生态位维度都过度重 叠的物种不能在相同斑块内共存, 而那些在相同斑 块内共存的物种必须在某些资源利用或生态位维 度上(如体型大小或营养级形态)有所分化, 才能利 用不同的资源。在哥伦比亚东部平原的一个热带牧 场, 相似的蚯蚓物种在不同的隔离斑块内呈现空间 隔离分布，尽管这些物种在垂直分布和体型大小方 面有微弱差异, 但是在同一斑块内它们的形态过于 相似，对资源有强烈的潜在竞争(Decaëns \& Rossi, 2001), 而它们的生态位分异又过低, 所以种间竞争 是这些虾蚓空间格局的重要驱动过程(Jiménez et al, 2006; Decaëns et al, 2009)。物种共存分析被越来越 多地用于检验种间竞争是否起调控作用(Gotelli \& McCabe, 2002)。研究证明, 蚂蚁(Traniello \& Levings,
1986; Gotelli \& Ellison, 2002; Sanders et al, 2003)、蚳 蚓(Fragoso \& Rojas, 1997; Decaëns et al, 2008, 2009; Decaëns, 2010; Jiménez et al, 2012)、地表步甲 (Brandl \& Topp, 1985)、跳虫和螨类(Caruso et al, 2013)和陆地软体动物(Barker \& Mayhill, 1999)的物 种共同出现的实测值显著低于模拟值，表明种间竞 争是这些土壤动物群落维持的重要调控过程。但实 际上群落内土壤动物食性复杂, 处于不同营养级。 例如在德国多个森林生境内, 一个群落内的甲螨属 于3-4个营养级(Schneider et al, 2004; Maraun et al, 2011), 用不考虑营养级关系的物种共存格局解释 种间竞争作用时有一定局限。因此, 量化群落内物 种的营养功能群是进一步验证土壤动物群落种间 竞争作用的基础(Chang et al, 2016)。虽然许多土壤 动物群落维持了很高的物种多样性, 但有关种内和 种间竞争调控的证据非常缺乏(Wardle, 2006)。一方 面, 土壤动物群落相同营养级之间相对较弱的竞争, 可能促使群落维持丰富的多样性(Wardle, 2006); 另 一方面，也说明种内和种间竞争对土壤动物群落的 调控作用相当复杂, 还需要开展深入细致的研究。

捕食是土壤动物群落的显著调控过程。与线 虫、线蚓、微型节肢动物和蚳蚓等次级消费者相比, 步甲、蜈蚣和蜘蛛等地表捕食者通常处于更高营养 级(Goncharov \& Tiunov, 2014), 它们不仅调控螨类 和虾蚓等较低营养级的消费者(Salmon et al, 2005; Gao et al, 2017b), 也调整局地营养级网络和维持群 落内的碎屑功能单位(Goncharov \& Tiunov, 2014)。 捕食对土壤动物群落的调控表现复杂, 研究表明蜈 蚣捕食显著地抑制跳虫数量(Salmon et al, 2005), 但 也有研究表明蜈蚣并不影响跳虫数量 (Gao et al, 2017b)。在许多生境特别是北方森林地表栖居的蜘 蛛、隐翅虫和蜈蚣等捕食者有很高的丰富度 (Petersen \& Luxton, 1982), 然而有关这些捕食者对 土壤动物群落调控作用的研究非常缺乏(Goncharov \& Tiunov, 2014)。

资源竞争和天敌危害可能导致密度制约效应 (density dependence) (祝燕等, 2009)。密度制约效应 被认为是维持物种多样性的重要机制, 它对群落的 调控作用已被公认(陈䂞等, 2014)。密度制约假说强 调群落内共存的物种具有生态位差异, 因而种内竞 争远大于种间竞争(Levine \& HilleRisLambers, 2009; 陈磊等, 2014); 而同种或亲缘关系较近的物种通过 
竞争资源和化感作用等方式相互损害, 从而为其他 物种的生存提供了空间和资源, 促进物种共存(王 婷等, 2014)。密度制约调控不同土壤动物功能群的 密度、数量和生长率等, 包括地表捕食性蜘蛛 (Takada \& Miyashita, 2014)、蚂蚁及蚂蚁和蚜虫之间 的共生关系(Addicott, 1979)、菌食性跳虫和捕食性 螨类(Ferguson \& Joly, 2010)、腐食性蚯蚓(Kammenga et al, 2003)等。密度制约还促进土壤动物集 群及其巢穴空间格局的形成, 当蚂蚁密度很高而能 够利用的领域受限时, 激烈的竞争可能会产生密度 依赖空间格局(pattern of density-dependent spacing) (Ryti，1991), 但也有研究发现密度制约并不调控蚂 蚁的空间格局(Schooley \& Wiens, 2003)。密度制约 还会调控捕食者一猎物之间的关系, 如调控步甲幼 虫的数量, 导致步甲幼虫种内竞争的变化, 进而改 变其猎物鼻涕虫(Deroceras reticulatum和Arion intermedius)的密度(Thomas et al, 2009)。但密度制约 对土壤动物群落的调控研究主要集中于少数类群, 相关研究还有待于进一步开展。

除了种间竞争和捕食这两个研究较多的生物 间作用(Hillebrand \& Blenckner, 2002)外，非营养级 生物间作用也起正的或者负的调控作用。土壤动物 通过改变物理环境和创造特定微生境来间接调控 其他土壤动物群落。如微型土壤节肢动物将调落叶 转换成粪粒, 虾蚓产生蚓粪, 白蚁建造土堆, 蚂蚁 产生土堆巢穴, 这些结构会产生异质性的有机质斑 块或促进空间结构的变异性, 从而影响其他土壤动 物群落的空间分布和构建过程。蚯蚓可以为其他土 壤动物营造适宜生境, 虾蚓数量多的生境中微型节 肢动物的密度也随之增加 (Hamilton \& Sillman, 1989; Loranger et al, 1998)。因为虾蚓活动增大土壤 孔隙度, 促进了其他土壤节肢动物扩散(Cameron et al, 2013), 优化跳虫躲避捕食的逃跑路线, 如蝶蚓 粪便的聚集堆积为跳虫提供躲避捕食者的场所 (Salmon et al, 2005), 所以蚯蚓改善后的土壤孔隙度 吸引了跳虫(Wickenbrock \& Heisler, 1997), 蝶蚂洞 穴和蚯蚓粪增加了跳虫数量(Tiunov \& Kuznetsova, 2000)和甲螨多样性(Loranger et al, 1998)。但是, 不 同营养级间的相互作用也会抑制其他土壤动物群 落, 如地下蚁巢降低食真菌线虫的密度(Blomqvist et $\mathrm{al}, 2000)$, 蚯蚂活动降低微型螨类和跳虫的丰富 度和物种多样性(Mclean \& Parkinson, 2000)。可能
是因为蚳蚓取食了跳虫产在调落物上的卵，从而抑 制了其数量(Gao et al, 2017b), 也可能是因为蚚蚓 与跳虫、螨类的取食调落物行为产生微弱的竞争 (Brown, 1995), 或者蛏蚓的取食和掘穴行为干扰了 真菌的生长, 降低了作为跳虫食物资源的真菌总量, 从而间接抑制了跳虫数量(Chang et al, 2016; Gao et al, 2017b)。近年来级联效应(cascade effects), 即捕 食者多样性对食物网结构和动态的影响备受关注 (邵元虎等, 2015)。蜘蛛、步甲等捕食者强烈影响其 猎物的多度、多样性和行为(Miyashita \& Niwa, 2006; Zhao et al, 2013), 这些影响又通过猎物的取食逐步 向更低营养级传递。这种自上而下的级联效应可以 改变地下食物网内一个种群、群落或者整个营养级 的丰富度、生物量和生产力(Pace et al, 1999), 进而 间接影响植物生物量、进入土壤生态系统的有机物 质、养分循环特征等(Croll et al, 2005; Wardle et al, 2005; Miyashita \& Niwa, 2006)。

\section{2 环境过滤}

土壤能提供三维的空间资源和高度异质的环 境条件(Wardle, 2002), 环境异质性增加微生境多样 性和资源分异性, 允许群落物种共存(Anderson, 1975; Giller, 1996; Schneider et al, 2004)。异质性环 境比均质性环境能够维持更多的物种(Tamme et al, 2010), 这种生态位的分化导致较高的土壤动物物 种多样性，并将物种排序成相对异质的局地空间格 局(Dornelas et al, 2006)。这种环境异质性导致土壤 动物群落高密度和低密度斑块的镶嵌分布格局 (Jiménez et al, 2006)。

土壤资源的空间异质性导致微生境的多样性， 较大的资源分化促进物种共存。例如，在较小空间 尺度的土壤和调落物生境, 小型节肢动物的物种丰 富度随着微生境多样性的增加而增加(Anderson, 1978; Hansen \& Coleman, 1998)。然而在土壤微宇宙 实验中，小型土壤节肢动物多样性在 4 种资源充分 混合的系统中很低，而在相同的4种资源构成的斑 块系统中，其多样性却较高，这表明空间分化降低 了竞争压力(Oconnell \& Bolger, 1998)。可见，土壤 资源的空间异质性不仅能促进微生境多样性，也会 使竞争性土壤动物发生空间分化。

小尺度空间环境条件相对均质，通常认为环境 异质性对小尺度群落空间格局不起调控作用，但是 单个植物和根系构型、动物的行为(Rossi, 2003a)和 
微地形(Ettema \& Wardle, 2002)都会强烈影响虾蚓 的空间格局。在 $40 \mathrm{~cm} \times 60 \mathrm{~cm}$ 的泥炭藓覆盖表面, 有壳变形虫在1-10 $\mathrm{cm}$ 斑块内聚集，几厘米范围内 的微地形变异起到了重要作用 (Mitchell et al, 2000)。即使地形和土壤环境相对均质，由于该生境 同时镶嵌在更大的空间尺度内, 土壤动物群落也在 几厘米到几米的范围内表现出斑块状分布。如多年 耕作和单一栽培种植对农田土壤产生同质性影响, 但主要线虫群落仍明显地聚集在6-80 $\mathrm{m}$ 的空间斑 块内(Robertson \& Freckman, 1995), 说明人类耕种 活动对胞囊线虫的空间格局有明显的影响(Webster \& Boag, 1992)。

在局地尺度, 土壤动物群落常从十几米到上百 米的范围内表现出空间格局 (Ettema \& Wardle, 2002)。首先，这种空间格局受土壤理化性质、营养 状态和污染状态空间异质性的影响 (Ettema \& Wardle, 2002; Bardgett, 2005; Khalil et al, 2009; Krab et al, 2010; Berg, 2012)。如农田土壤跳虫在大于 200 $\mathrm{m}$ 的范围内具有显著的空间格局, 这受较大尺度的 土壤有机质和农业活动影响(Fromm et al, 1993)。美 国乔治亚海岸平原的河岸湿地内, 一种食细菌线虫 的分布斑块达到了 $67 \mathrm{~m}$, 该空间格局受土壤湿度和 硝态氮影响, 但这种影响强度随时间变化(Ettema et al，1998); 而在苏格兰东部一个农业生态系统中, 线虫在5-50 m范围内的空间格局受人类农业活动 的影响(Webster \& Boag, 1992)。其次, 土壤动物群 落的空间格局也受到植物异质性的调控, 包括植物 大小、生长型和时间动态变化。如在混交林中, 不 同树种的调落物质量差异能够促进微生境异质性 (Saetre, 1999; Saetrea \& Bååthb, 2000), 因而地表植 被的分异是土壤动物群落格局和构建的关键驱动 力。另外, 土壤和植被等环境的异质性会同时调控 土壤动物群落格局。美国科罗拉多州北部矮草草原 的白蚁群落在 $330 \mathrm{~m}$ 的范围内形成显著的空间格局, 这是由于较大尺度地形和植被空间异质性的影响 (Crist, 1998)。擅长制造土堆的动物(如蚂蚁)会增加 土壤环境异质性, 它们与植物交互作用进而影响土 壤动物群落格局的斑块性(Ayarbe \& Kieft, 2000; Blomqvist et al, 2000)。

在较大的景观尺度, 土壤湿度、 $\mathrm{pH}$ 值和资源可 获得性的环境异质性强烈地影响温带森林土壤甲 螨的群落组成和多样性(Maraun \& Scheu, 2010)。但
也有研究发现在景观尺度，营养状态、水的可获得 性、土壤类型和植被类型的环境异质性对甲螨空间 分布格局的解释能力微弱，反而是地质年龄 (Zaitsev et al, 2013)、气候和景观历史(Rantalainen et al, 2005; Zaitsev et al, 2006)对其分布格局有显著 的调控作用。

\section{3 随机扩散}

大型土壤动物在土壤基质内的扩散能力相对 较弱，而中小型土壤动物可能通过其他(土壤)动物、 水和风等媒介长距离被动扩散。土壤动物沿着土壤 基质的主动扩散一般非常受限，它们的每日移动距 离从几毫米到几厘米, 不同种类的移动距离有所差 异(Bengtsson, 1997; Dighton, 1997)。如线虫的移动 受到土壤生境复杂性的影响(Jabbour \& Barbercheck, 2008), 一些节肢动物在地下移动比在地上慢 4 倍 (Kaczmarek, 1978)。当物种的移动距离比资源斑块 小很多的时候，许多物种能够在单一的资源环境中 共存(Tilman \& Kareiva, 1997), 土壤动物的多尺度 空间格局便受到随机扩散过程的调控。即使在相对 均质的生境, 繁殖和限制性扩散等内在过程也会导 致土壤动物的聚集分布(Oconnell \& Bolger, 1998)。 如瑞士侏罗山高位沼泽内, 内在过程使有壳变形虫 在13个厘米级尺度内形成聚集空间格局(Mitchell et al, 2000); 马提尼克(Martinique)一个草地生境中, 蚟蚓卵和成体扩散行为使其呈10-30 m的斑块状集 群分布(Rossi et al, 1997)。

扩散对群落格局能产生不同的调控结果(Cadotte \& Fukami, 2005), 因此很难解释其作用。不同斑 块间的生境廊道可以促进不同生境间土壤动物的 扩散, 在援救效应(Rescue effect)的调控下维持其他 隔离生境的群落组成和格局。在微宇宙实验中 (Rantalainen et al, 2004), 生境廊道显著增加了线蚓 的多度和生物量，但并没有显著提高土壤跳虫、螨 类和线虫的多度，可能是因为不同生境间的扩散距 离与线蚓的扩散能力、体型大小相匹配，而其他类 群由于扩散能力较弱, 适应生存于扩散受限制的资 源型斑块中。而野外调查实验发现跳虫扩散能力对 群落维持有重要调控作用, 地表跳虫的强扩散能力 使其能够快速地重新定殖被洪水淹没过的生境，使 群落内部不同生境间的 $\beta$ 多样性降低, 并增加群落 内部物种组成的相似性(Russell \& Griegel, 2006)。当 空间范围扩大到区域尺度，群落内不同生境间的隔 
离度增加而连接度降低, 随着空间距离增加, 跳虫 的扩散能力减弱, 从而增加了不同生境之间物种组 成的异质化, 导致 $\beta$ 多样性和 $\gamma$ 多样性的增加 (Starzomski \& Srivastava, 2007)。

扩散能力和扩散模式是决定群落物种共存的 关键。扩散能力强的物种因为更容易到达适宜生境, 所以较少受到生态位和空间结构的限制(Padial et al, 2014), 而扩散模式(主动扩散和被动扩散)对群落结 构的影响较复杂(Bie et al, 2012)。土壤螨移动缓慢 (Terauds et al, 2011), 无论是主动扩散还是被动扩 散的螨类, 其空间格局均受扩散限制影响, 因此螨 类很难突破环境生态位的限制, 其群落格局常受到 环境异质性的调控(Mumladze et al, 2013)。具短翅的 步甲飞翔能力相对较弱, 群落内不同生境间 $\beta$ 多样 性差异较大, 而具长翅的步甲移动能力较强, 不同 生境间 $\beta$ 多样性差异较小(Hendrickx et al, 2009)。不 同于土壤螨群落, 地表步甲这种强扩散能力和主动 扩散模式使其能够突破环境生态位的限制并到达 适宜生境, 从而削弱环境异质性对群落的调控。

长距离扩散是通过非常见扩散途径实现的低 频率扩散事件, 关注长距离扩散可促进对土壤动物 群落分布格局和驱动机制的深入研究 (Nathan, 2006)。土壤食根线虫可以通过风媒和水媒进行长距 离扩散(Peña et al, 2011); 土壤螨类和跳虫可以在海 水表面和水下存活 2 周左右, 其被动扩散距离可达 $700 \mathrm{~km}$, 理论上可以随着洋流从挪威北部扩散到斯 瓦尔巴特群岛(Coulson et al, 2010)。这种强扩散能 力和独特的繁殖模式使土壤动物广泛分布(Moore, 2002)。另外, 地质历史事件、地理障碍和空间地理 距离等也会影响土壤动物的随机扩散(Wiensr \& Milne, 1989), 进而影响其空间格局和群落构建 (Moore, 2002)。

农业、渔业和其他人为活动导致的外来物种入 侵是一种不可忽视的随机过程, 也对土壤动物群落 构建起到重要的调控作用(Cameron et al, 2007; Wackett et al, 2018)。蛏蚓和蚂蚁是两类最主要的入 侵土壤动物(Coyle et al, 2017), 二者可以改变土壤 结构、化学属性、土壤微生物群落并加剧土壤动物 间资源竞争(Eisenhauer et al, 2007)。外来入侵蝶蚓 可以显著降低土壤跳虫、螨等小型节肢动物的密度 和物种数量(Migge, 2001; Eisenhauer et al, 2007), 但也可能通过改善微生境、提供避难所和提供食物
资源等增加线虫、革螨的丰富度(Maraun et al, 1999)。外来入侵蚂蚁通过直接捕食或资源竞争降低 本地蚂蚁、跳虫和螨等土壤动物的丰富度(Walker, 2006), 但在一些案例中, 若时间充足, 本地蚂蚁也 会恢复到外来蚂蚁入侵之前的丰富度(Morrison, 2002)。外来入侵植物可能会改变进入本地土壤生态 系统的植物资源的质量、数量、空间分布以及土壤 温湿度和根系分布等，进而影响土壤线虫、节肢动 物、蛏蚓等群落的物种丰富度和个体数量(Belnap et al, 2005; Belnap \& Phillips, 2011; Coyle et al, 2017)。 尽管已经开展了相关研究，但人类活动导致的外来 物种入侵到底如何调控土壤动物多样性, 其潜在的 调控机制如何，仍然所知甚少(Wardle, 2006)。

我国土壤动物群落构建机制研究表明，土壤动 物群落格局受到结构性因素、随机性因素或两者的 共同影响, 这说明土壤动物群落受到确定性和非确 定性过程的共同调控。首先，研究表明随机扩散对 土壤动物群落的调控尤其显著(高梅香等, 2014b; Sha et al, 2015), 但这种扩散因类群而异: 土壤螨较 弱的扩散能力对群落构建有限制作用(Dong et al, 2017), 而地表甲虫因有较强的扩散能力, 群落在不 同样点之间具有较高的物种周转率(高梅香等, 2018)。其次，虽然有研究表明环境过滤对群落组成 没有很强的解释能力, 但其调控作用仍不容忽视 (张丽梅等, 2016)。土壤和地形等因子是影响土壤动 物群落空间格局的重要因素, 目前的研究可能忽略 了某些更关键的环境过程，导致我们难以发现环境 过滤的显著调控作用。第三, 土壤动物群落表现为 竞争型、聚集型和随机型多种格局(Lin et al, 2014; 高梅香等, 2016), 种间竞争对土壤动物群落的调控 作用并不普遍(Gao et al, 2017a; 倪娟平等, 2018a), 但这并不能否认生物间作用的调控过程。

总之, 目前研究表明生态位理论和中性理论是 土壤动物群落多尺度格局和共存的重要机制(Gao et al, 2014), 随机扩散和环境过滤的作用相对明显 (Sha et al, 2015), 而生物间作用的调控证据仍不充 足(Gao et al, 2016)。

\section{总结与展望}

环境过滤、生物间作用和随机扩散对土壤动物 群落构建的调控研究取得了很大进展，然而仍然面 临一些挑战, 如环境过滤的定义和应用受到一些学 
者的批评(Kraft et al, 2015), 竞争、捕食和寄生等生 物间作用对群落的调控能力研究主要集中于少数 类群, 量化土壤动物群落的扩散过程仍然是一个难 点。解决上述问题会极大地促进土壤动物群落构建 机制的研究，这也是未来发展的重要方向。

\section{1 环境过滤对土壤动物群落的调控}

经典的环境过滤被定义为环境条件选择那些 有能力在给定地点存活和维持的物种(Emerson \& Gillespie, 2008), 但这个概念忽视了生态学过程的 复杂性。物种在某个群落的缺失反映的不仅是环境 过滤导致的物种排除，也有其他机制的作用(Kraft et al, 2015), 如扩散限制和局地竞争, 目前的研究 常常不能区分这些机制(Cadotte \& Tucker，2017), 因此, 环境过滤的概念和应用应该被严格限定 (Kraft et al, 2015)。受到这些观点的启发, 一些学者 直接使用选择性过滤而不是环境过滤来表征生物 因子和非生物因子对有机体适合度的影响(Graham \& Stegen, 2017)。但也有研究认为在特定的背景下 量化或应用环境过滤的概念仍然恰当(Thakur \& Wright, 2017), 解释环境重要性时不应仅依赖于群 落组成数据, 还应该综合考虑物种丰富度、种群生 长或性状(Cadotte \& Tucker, 2017)。另外，根据系统 发育距离或性状距离来分析“系统发育-环境”或“性 状一环境”之间的关系, 是解释环境过滤是否起作用 的有效途径。当群落物种具有相同的性状时, 可认 为环境过滤起调控作用; 当群落内物种性状有明显 变异时, 可认为生物间作用起调控作用。但生物间 作用也可以导致与环境无关的性状产生相似性 (Mayfield \& Levine, 2010)。为了解释上述矛盾, Thakur和Wright (2017)提出一个框架, 即正确区别 宏环境 (macroenvironment) 和微环境 (microenvironment)之间的差别, 以及正确区分物种对宏环境 的影响和这些影响反过来对物种的影响。关于环境 过滤作用的深入研究, 会促进我们对土壤动物群落 构建机制的认识(Kraft et al, 2015)。

\section{2 基于食性关系的生物相互作用}

虽然很多研究发现了生物间作用对土壤动物 群落的调控作用, 但相关研究仍然非常缺乏。原因 之一是很多研究将土壤生物群落视作一个黑箱或 集中于特定的类群(Morrien et al, 2017), 如线蚓、蚯 蚓、步甲和地表蜘蛛等, 而对于土壤动物群落整体 网络和真正的营养级关系所知甚少。稳定同位素技
术能够确定不同时空尺度下食物来源、竞争关系、 捕食-被捕食关系、食物网连通性、营养生态位宽 度和摄食行为等 (窦永静等, 2015; 陈展彦等, 2017)。明确群落内物种之间的基本营养关系是进一 步阐明生物间作用对群落调控能力的基础。基于稳 定同位素技术的分析是研究土壤动物群落食物网 结构和营养级关系的有效途径(Tiunov, 2007), 会极 大地促进生物间作用对土壤动物群落构建调控作 用的研究(Gao et al, 2014)。

\section{3 扩散对土壤动物群落构建的调控作用}

量化土壤动物群落的扩散能力是一个难点, 也 是土壤动物群落构建机制研究的一个障碍。土壤动 物体型较小, 生存环境隐蔽性强, 无论是单个个体 还是单个物种, 野外监测其扩散能力和扩散模式都 极其困难(Heino et al, 2017)。一个群落常包含几十 个物种, 在自然环境中直接获取群落内所有物种的 扩散参数几乎是不可能的。借鉴相关研究成果，土 壤动物群落扩散能力可以通过多种指标来表征 (Heino et al, 2017): (1)基于有机体的扩散指标，包 括土壤动物的体型大小、翅的有无、翅长或翅宽、 扩散模式等。例如，非常微小的土壤动物更容易被 水、风或动物等搬运到较远的地方, 而体型较大的 土壤动物被长距离搬运的可能性降低。翅长、翅宽 是土壤动物扩散能力的指标, 如长翅步甲的扩散能 力相对较强, 而短翅步甲的扩散能力相对较弱。以 上指标的获得依赖于土壤动物功能性状参数, 即那 些在个体水平可测量的, 通过影响物种的生长、繁 殖或存活来影响物种适合度的生物特征(Violle et al, 2007), 反映了土壤动物对外部环境的适应和权衡。

(2)基于分子遗传的扩散指标。种群遗传学、DNA 条形码和环境DNA等生物技术和指标可以作为土 壤动物及其群落的扩散指标。如不同谱系关系的地 理分布能通过种群的空间遗传变异性来指示历史 扩散事件。相关研究已证明基因结构和物种扩散能 力有联系, 具有高基因多样性的种群的扩散能力相 对较低(Heino et al, 2017)。(3)基于图形的扩散指标 (Heino et al, 2017)。该方法可以评估地形结构和地 理距离对土壤动物移动的影响, 如PCNM和Moran 特征向量图等(Dray et al, 2006)。

土壤动物是研究群落生态学基本问题的理想 实验对象(Gerisch, 2011), 但是以土壤动物为对象 的群落构建理论的验证非常少。群落构建机制假说 
或理论包括Lotka-Volterra竞争模型、竞争-拓殖权衡 假说、资源比例假说、更新生态位假说、中性理论、 近中性理论(牛克昌等, 2009)和集合群落理论 (Leibold et al, 2004)等, 目前以土壤动物为对象的 群落构建机制研究, 多基于模型验证生态位理论和 中性理论、集合群落理论、确定性过程和非确定性 过程的调控作用，而对其他理论的深入解释和验证 明显不足。土壤动物群落格局和构建机制研究已取 得了重要进展，我国相关研究虽然刚刚起步，但有 很大的发展潜力, 需要土壤动物学家共同努力, 促 进该领域的深入发展。

\section{参考文献}

Addicott JF (1979) A multispecies aphid-ant association: Density dependence and species-specific effects. Canadian Journal of Zoology, 57, 558-569.

Anderson JM (1975) The Enigma of Soil Animal Species Diversity. Springer, Dordrecht.

Anderson JM (1978) A method to quantify soil-microhabitat complexity and its application to a study of soil animal species diversity. Soil Biology \& Biochemistry, 10, 77-78.

Anderson TL, Mott CL, Levine TD, Whiteman HH (2013) Life cycle complexity influences intraguild predation and cannibalism in pond communities. Copeia, 2013, 284-291.

Anderson TL, Whiteman HH (2015) Asymmetric effects of intra- and interspecific competition on a pond-breeding salamander. Ecology, 96, 1681-1690.

Ayarbe JP, Kieft TL (2000) Mammal mounds stimulate microbial activity in a semiarid shrubland. Ecology, 81, 1150-1154.

Baguette M, Blanchet S, Legrand D, Stevens VM, Turlure C (2013) Individual dispersal, landscape connectivity and ecological networks. Biological Reviews of the Cambridge Philosophical Society, 88, 310-326.

Bardgett RD (2002) Causes and consequences of biological diversity in soil. Zoology, 105, 367-375.

Bardgett RD (2005) The Biology of Soil: A Community and Ecosystem Approach. Oxford University Press, Oxford.

Bardgett RD, Yeates GW, Anderson JM (2005) Patterns and Determinants of Soil Biological Diversity. Cambridge University Press, Cambridge.

Barker GM, Mayhill PC (1999) Patterns of diversity and habitat relationships in terrestrial mollusc communities of the Pukeamaru Ecological District, northeastern New Zealand. Journal of Biogeography, 26, 215-238.

Beale CM, Lennon JJ, Yearsley JM, Brewer MJ, Elston DA (2010) Regression analysis of spatial data. Ecology Letters, 13, 246-264.

Bell G (2000) The distribution of abundance in neutral communities. The American Naturalist, 155, 606-617.

Bell T (2010) Experimental tests of the bacterial distance-decay relationship. The ISME Journal, 4, 1357-1365.

Belnap J, Phillips SL (2011) Soil biota in an ungrazed grassland: Response to annual grass (Bromus tectorum) invasion. Ecological Applications, 11, 1261-1275.

Belnap J, Phillips SL, Sherrod SK, Moldenke A (2005) Soil biota can change after exotic plant invasion: Does this affect ecosystem processes? Ecology, 86, 3007-3017.

Bengtsson G (1997) Dispersal, heterogeneity and resistance: Challenging soil quality assessment. In: Ecological Risk Assessment of Contaminants in Soil (eds Straalen N, Lokke H), pp. 191-212. Chapman \& Hall, London.

Berg MP (2012) Patterns of Biodiversity of Fine and Small Spatial Scales. Oxford University Press, Oxford.

Bie TD, Meester LD, Brendonck L, Martens K, Goddeeris B, Ercken D, Hampel H, Denys L, Vanhecke L, Gucht KV, Wichelen JV, Vyverman W, Declerck SAJ (2012) Body size and dispersal mode as key traits determining metacommunity structure of aquatic organisms. Ecology Letters, 15, 740-747.

Blanchet FG, Bergeron JAC, Spence JR, He FL (2013) Landscape effects of disturbance, habitat heterogeneity and spatial autocorrelation for a ground beetle (Carabidae) assemblage in mature boreal forest. Ecography, 36, 636-647.

Blomqvist MM, Olff H, Blaauw MB, Bongers T, van der Putten WH (2000) Interactions between above- and belowground biota: Importance for small-scale vegetation mosaics in a grassland ecosystem. Oikos, 90, 582-598.

Borcard D, Legendre P (2002) All-scale spatial analysis of ecological data by means of principal coordinates of neighbour matrices. Ecological Modelling, 153, 51-68.

Brandl R, Topp W (1985) Size structure of Pterostichus spp. (Carabidae) -Aspects of competition. Oikos, 44, 234-238.

Brown GG (1995) How do earthworms affect microfloral and faunal community diversity? Plant and Soil, 170, 209-231.

Cadotte MW, Fukami T (2005) Dispersal, spatial scale, and species diversity in a hierarchically structured experimental landscape. Ecology Letters, 8, 548-557.

Cadotte MW, Tucker CM (2017) Should environmental filtering be abandoned? Trends in Ecology \& Evolution, 32, 429-437.

Cameron EK, Bayne EM, Clapperton MJ (2007) Humanfacilitated invasion of exotic earthworms into northern boreal. Ecoscience, 14, 482-490.

Cameron EK, Proctor HC, Bayne EM (2013) Effects of an ecosystem engineer on belowground movement of microarthropods. PLoS ONE, 8, e62796.

Caruso T, Chan Y, Lacap DC, Lau MCY, McKay CP, Pointing SB (2011) Stochastic and deterministic processes interact in the assembly of desert microbial communities on a global scale. The ISME Journal, 5, 1406-1413.

Caruso T, Taormina M, Migliorini M (2012) Relative role of deterministic and stochastic determinants of soil animal community: A spatially explicit analysis of oribatid mites. Journal of Animal Ecology, 81, 214-221. 
Caruso T, Trokhymets V, Bargagli R, Convey P (2013) Biotic interactions as a structuring force in soil communities: Evidence from the micro-arthropods of an Antarctic moss model system. Oecologia, 172, 495-503.

Chang CH, Szlavecz K, Filley T, Buyer JS, Bernard MJ, Pitz SL (2016) Belowground competition among invading detritivores. Ecology, 97, 160-170.

Chase JM, Leibold MA (2002) Spatial scale dictates the productivity-biodiversity relationship. Nature, 416, 427-430.

Chen L, Mi XC, Ma KP (2014) Niche differentiation and its consequence on biodiversity maintenance in forest communities. Chinese Bulletin of Life Sciences, 26, 112-117. (in Chinese with English abstract) [陈䂞, 米湘成, 马克平 (2014) 生态位分化与森林群落物种多样性维持研究展 望. 生命科学, 26, 112-117.]

Chen ZY, Wu HT, Wang YB, Lv XG (2017) Research progress on food sources and food web structure of wetlands based on stable isotopes. Chinese Journal of Applied Ecology, 28, 2389-2398. (in Chinese with English abstract) [陈展彦, 武 海涛, 王云彪, 吕宪国 (2017) 基于稳定同位素的湿地食 物源判定和食物网构建研究进展. 应用生态学报, 28 , 2389-2398.]

Coulson SJ, Hodkinson ID, Webb NR, Harrison JA (2010) Survival of terrestrial soil-dwelling arthropods on and in seawater: Implications for trans-oceanic dispersal. Functional Ecology, 16, 353-356.

Coyle DR, Nagendra UJ, Taylor MK, Campbell JH, Cunard CE, Joslin AH, Mundepi A, Phillips CA, Mac AC (2017) Soil fauna responses to natural disturbances, invasive species, and global climate change: Current state of the science and a call to action. Soil Biology \& Biochemistry, 110, 116-133.

Crist TO (1998) The spatial distribution of termites in shortgrass steppe: A geostatistical approach. Oecologia, 114, 410-416.

Croll DA, Maron JL, Estes JA, Danner EM, Byrd GV (2005) Introduced predators transform subarctic islands from grassland to tundra. Science, 307, 1959-1961.

de Ruiter PC, Neutel AM, Moore JC (1995) Energetics, patterns of interaction strengths, and stability in real ecosystems. Science, 269, 1257-1260.

DeAngelis DL, Yurek S (2017) Spatially explicit modeling in ecology: A review. Ecosystems, 20, 284-300.

Decaëns T (2000) Degradation dynamics of surface earthworm casts in grasslands of the eastern plains of Colombia. Biology and Fertility of Soils, 32, 149-156.

Decaëns T (2010) Macroecological patterns in soil communities. Global Ecology and Biogeography, 19, 287-302.

Decaëns T, Jiménez JJ, Rossi JP (2009) A null-model analysis of the spatio-temporal distribution of earthworm species assemblages in Colombian grasslands. Journal of Tropical Ecology, 25, 415-427.

Decaëns T, Margerie P, Aubert M, Hedde M, Bureau F (2008) Assembly rules within earthworm communities in north- western France-A regional analysis. Applied Soil Ecology, 39, 321-335.

Decaëns T, Rossi JP (2001) Spatio-temporal structure of an earthworm community and soil heterogeneity in a tropical pasture. Ecography, 24, 671-682.

Diamond J (1975) Assembly of Species Communities. Harvard University Press, Cambridge.

Dighton J, Jones HE, Robinson CH, Beckett J (1997) The role of abiotic factors, cultivation practices and soil fauna in the dispersal of genetically modified microorganisms in soil. Applied Soil Ecology, 5, 109-131.

Diniz JAF, Bini LM, Hawkins BA (2003) Spatial autocorrelation and red herrings in geographical ecology. Global Ecology and Biogeography, 12, 53-64.

Dong CX, Gao MX, Guo CW, Lin L, Wu DH, Zhang LM (2017) The underlying processes of a soil mite metacommunity on a small scale. PLoS ONE, 12, e0176828.

Dong XY, Li B, He FZ, Gu Y, Sun MQ, Zhang HM, Tan L, Xiao W, Liu SR, Cai QH (2016) Flow directionality, mountain barriers and functional traits determine diatom metacommunity structuring of high mountain streams. Scientific Reports, 6, 24711.

Dornelas M, Connolly SR, Hughes TP (2006) Coral reef diversity refutes the neutral theory of biodiversity. Nature, 440, 80-82.

Dou YJ, Chang L, Wu DH (2015) Research methods of soil animal food web: A review. Chinese Journal of Ecology, 34, 247-255. (in Chinese with English abstract) [窦永静, 常亮, 吴东辉 (2015) 土壤动物食物网研究方法. 生态学杂志, 34, 247-255.]

Dray S, Legendre P, Peres-Neto PR (2006) Spatial modelling: A comprehensive framework for principal coordinate analysis of neighbour matrices (PCNM). Ecological Modelling, 196, 483-493.

Eisenhauer N, Partsch S, Parkinson D, Scheu S (2007) Invasion of a deciduous forest by earthworms: Changes in soil chemistry, microflora, microarthropods and vegetation. Soil Biology \& Biochemistry, 39, 1099-1110.

Emerson BC, Gillespie RG (2008) Phylogenetic analysis of community assembly and structure over space and time. Trends in Ecology \& Evolution, 23, 619-630.

Ettema CH, Coleman DC, Vellidis G, Rathbun S (1998) Spatiotemporal distributions of bacterivorous nematodes and soil resources in a restored riparian wetland. Ecology, 79, 2721-2734.

Ettema CH, Rathbun SL, Coleman DC (2000) On spatiotemporal patchiness and the coexistence of five species of Chronogaster (Nematoda: Chronogasteridae) in a riparian wetland. Oecologia, 125, 444-452.

Ettema CH, Wardle DA (2002) Spatial soil ecology. Trends in Ecology \& Evolution, 17, 177-183.

Ferguson SH, Joly DO (2010) Dynamics of springtail and mite populations: The role of density dependence, predation, and weather. Ecological Entomology, 27, 565-573. 
Fortin MJ, Dale MRT (2005) Spatial Analysis: A Guide for Ecologists. Cambridge University Press, Cambridge, New York.

Fragoso C, Rojas P (1997) Size shift in the Mexican earthworm species Balanteodrilus pearsei (Megascolecidae, Acanhodrilini): A possible case of character displacement. Soil Biology \& Biochemistry, 29, 237-240.

Fromm H, Winter K, Filser J, Hantschel R, Beese F (1993) The influence of soil type and cultivation system on the spatial distributions of the soil fauna and microorganisms and their interactions. Geoderma, 60, 109-118.

Gao MX, Cheng SS, Ni JP, Lin L, Lu TY, Wu DH (2017a) Negative spatial and coexistence patterns and species associations are uncommon for carrion beetles (Coleoptera: Silphidae) at a small scale. European Journal of Soil Biology, 83, 52-57.

Gao MX, He P, Liu D, Guo CW, Zhang XP, Li JK (2014a) Multi-scale spatial autocorrelation of soil mite community in a temperate deciduous broad-leaved forest, Northeast China. Chinese Journal of Soil Science, 45, 1104-1112. (in Chinese with English abstract) [高梅香, 何萍, 刘冬, 郭传伟, 张雪 萍, 李景科 (2014a) 温带落叶阔叶林土壤螨群落多尺度 空间自相关性. 土壤通报, 45, 1104-1112.]

Gao MX, He P, Zhang XP, Liu D, Wu DH (2014) Relative roles of spatial factors, environmental filtering and biotic interactions in fine-scale structuring of a soil mite community. Soil Biology \& Biochemistry, 79, 68-77.

Gao MX, Li JK, Shi H, Zhang XP, Zhu JY (2016) Co-occurrence pattern dynamics of a Carabidae community in a Pinus koraiensis. Acta Ecologica Sinica, 36, 6591-6601. (in Chinese with English abstract) [高梅香, 李 景科, 石昊, 张雪萍, 朱纪元 (2016) 人工红松林步行虫 (Coleoptera: Carabidae)群落物种共存格局动态分析. 生态 学报, 36, 6591-6601.]

Gao MX, Liu D, Lin L, Wu DH (2016) The small-scale structure of a soil mite metacommunity. European Journal of Soil Biology, 74, 69-75.

Gao MX, Liu D, Wu DH, Zhang XP (2014b) Spatial autocorrelation of aboveground and belowground mite communities in farmland of the Sanjiang Plain. Acta Pedologica Sinica, 51, 163-171. (in Chinese with English abstract) [高梅香, 刘冬, 吴东辉, 张雪萍 (2014b) 三江平原农田地表和地 下土壤螨群落空间自相关性研究. 土壤学报, 51, 163-171.]

Gao MX, Liu D, Zhang XP, Wu DH (2016) Spatial relationships between the abundance of aboveground and belowground soil mite communities, and environmental factors in a farmland on the Sanjiang Plain, China. Acta Ecologica Sinica, 36, 1782-1792. (in Chinese with English abstract) [高梅香, 刘冬, 张雪萍, 吴东辉 (2016) 三江平原农田地 表和地下土壤螨类丰富度与环境因子的空间关联性. 生 态学报, 36, 1782-1792.]

Gao MX, Sun X, Qiao ZH, Hou HY, Lu TY, Wu DH, Jin GZ (2018) Distinct patterns suggest that assembly processes differ for dominant arthropods in above-ground and below-ground ecosystems. Pedobiologia, 69, 17-28.

Gao MX, Sun X, Wu DH, Zhang XP (2014c) Spatial autocorrelation at multi-scale of soil collembolan community in farmland of the Sanjiang Plain, Northeast China. Acta Ecologica Sinica, 34, 4980-4990. (in Chinese with English abstract) [高梅香, 孙新, 吴东辉, 张雪萍 (2014c) 三江平 原农田土壤跳虫多尺度空间自相关性. 生态学报, 34, 4980-4990.]

Gao MX, Taylor MK, Callaham MA (2017b) Trophic dynamics in a simple experimental ecosystem: Interactions among centipedes, Collembola and introduced earthworms. Soil Biology \& Biochemistry, 115, 66-72.

Gao MX, Zhu JY, Ni JP, Li JK, Lin L, Wu DH (2018) Beta diversities of ground-beetle assemblages in two broadleaved Korean pine (Pinus koraiensis) mixed forests in Xiao xing'an Mountains. Acta Ecologica Sinica, 38, 457-463. (in Chinese with English abstract) [高梅香, 朱纪元, 倪娟平, 李景科, 林琳, 吴东辉 (2018) 小兴安岭阔叶红松林地表 甲虫Beta多样性. 生态学报, 38, 457-463.]

Gascoigne JC, Beadman HA, Saurel C, Kaiser MJ (2005) Density dependence, spatial scale and patterning in sessile biota. Oecologia, 145, 371-381.

Gascón S, Arranz I, Cañedo-Argüelles M, Nebra A, Ruhí A, Rieradevall M, Caiola N, Sala J, Ibàñez C, Quintana XD, Boix D (2016) Environmental filtering determines metacommunity structure in wetland microcrustaceans. Oecologia, 181, 193-205.

Gaston KJ (2000) Global patterns in biodiversity. Nature, 405, 220-227.

Gerisch M (2011) Habitat disturbance and hydrological parameters determine the body size and reproductive strategy of alluvial ground beetles. Zookeys, 100, 353-370.

Giller P (1996) The diversity of soil communities, the 'poor man's tropical rainforest'. Biodiversity and Conservation, 5, 135-168.

Goncharov AA, Tiunov AV (2014) Trophic chains in the soil. Biology Bulletin Reviews, 4, 393-403.

Gotelli NJ, Ellison AM (2002) Assembly rules for New England ant assemblages. Oikos, 99, 591-599.

Gotelli NJ, McCabe DJ (2002) Species co-occurrence: A meta-analysis of JM. Diamond's assembly rules model. Ecology, 83, 2091-2096.

Graham EB, Stegen JC (2017) Dispersal-based microbial community assembly decreases biogeochemical function. Processes, 5, 1-18.

Gutiérrez-López M, Jesús JB, Trigo D, Fernández R, Novo M, Díaz-Cosín DJ (2010) Relationships among spatial distribution of soil microarthropods, earthworm species and soil properties. Pedobiologia, 53, 381-389.

Hamilton WE, Sillman DY (1989) Influence of earthworm middens on the distribution of soil microarthropods. Biology and Fertility of Soils, 8, 279-284.

Hansen RA, Coleman DC (1998) Litter complexity and 
composition are determinants of the diversity and species composition of oribatid mites (Acari: Oribatida) in litterbags. Applied Soil Ecology, 9, 17-23.

Heike K, Marc J, Jan K, Peter Z, Werner T (2009) Spatial patterns of litter-dwelling taxa in relation to the amounts of coarse woody debris in European temperate deciduous forests. Forest Ecology and Management, 257, 1255-1260.

Heino J, Alahuhta J, Ala-Hulkko T, Antikainen H, Bini LM, Bonada N, Datry T, Eros T, Hjort J, Kotavaara O, Melo AS, Soininen J (2017) Integrating dispersal proxies in ecological and environmental research in the freshwater realm. Environmental Reviews, 25, 334-349.

Hendrickx F, Maelfait JP, Desender K, Aviron S, Bailey D, Diekotter T, Lens L, Liira J, Schweiger O, Speelmans M, Vandomme V, Bugter R (2009) Pervasive effects of dispersal limitation on within- and among-community species richness in agricultural landscapes. Global Ecology and Biogeography, 18, 607-616.

Hillebrand H, Blenckner T (2002) Regional and local impact on species diversity-From pattern to processes. Oecologia, 132, 479-491.

Hu YY, Zhu JY, Yan L, Cao Y, Gao MX, Lu TY (2018) Analysis of the dynamic spatial pattern of adult Coleoptera communities at fine scale in a temperate deciduous broad-leaved forest. Acta Ecologica Sinica, 38, 1841-1851. (in Chinese with English abstract) [胡媛媛, 朱纪元, 间龙, 曹阳, 高梅 香, 卢廷玉 (2018) 温带落叶阔叶林地表鞘翅目成虫小 尺度空间格局动态分析. 生态学报, 38, 1841-1851.]

Hua JF, Jiang Y, Liang WJ (2008) Effects of vegetation coverage on the spatial distribution of soil nematode trophic groups. Frontiers of Biology in China, 3, 63-67.

Hubbell SP (2001) The Unified Neutral Theory of Biodiversity and Biogeography. Princeton University Press, Princeton.

Huston MA (1994) Biological Diversity. Cambridge University Press, Cambridge.

Jabbour R, Barbercheck M (2008) Soil and habitat complexity effects on movement of the entomopathogenic nematode Steinernema carpocapsae in maize. Biological Control, 47, 235-243.

Jiménez JJ, Decaëns T, Lavelle P, Rossi JP (2014) Dissecting the multi-scale spatial relationship of earthworm assemblages with soil environmental variability. BMC Ecology, 14, 1-19.

Jiménez JJ, Decaëns T, Rossi JP (2006) Stability of the spatiotemporal distribution and niche overlap in neotropical earthworm assemblages. Acta Oecologica, 30, 299-311.

Jiménez JJ, Decaëns T, Rossi JP (2012) Soil environmental heterogeneity allows spatial co-occurrence of competitor earthworm species in a gallery forest of the Colombian 'Llanos'. Oikos, 121, 915-926.

Jiménez JJ, Moreno AG, Decaëns T, Lavelle P, Fisher MJ, Thomas RJ (1998) Earthworm communities in native savannas and man-made pastures of the Eastern Plains of Colombia. Biology and Fertility of Soils, 28, 101-110.
Judas M (1988) The species-area relationship of European Lumbricidae (Annelida, Oligochaeta). Oecologia, 76, 579587.

Kaczmarek W (1978) Locomotory activity of soil fauna as a parameter of the trophic structure and of succession in forest ecosystems. Pedobiologia, 18, 434-441.

Kammenga JE, Spurgeon DJ, Svendsen C, Weeks JM (2003) Explaining density-dependent regulation in earthworm populations using life-history analysis. Oikos, 100, 89-95.

Khalil MA, Janssens TKS, Berg MP, Straalen NMV (2009) Identification of metal-responsive oribatid mites in a comparative survey of polluted soils. Pedobiologia, 52, 207-221.

Kingsolver JG, Pfennig DW (2004) Individual-level selection as a cause of Cope's rule of phyletic size increase. Evolution, 58, 1608-1612.

Kissling WD, Carl G (2008) Spatial autocorrelation and the selection of simultaneous autoregressive models. Global Ecology and Biogeography, 17, 59-71.

Krab EJ, Oorsprong H, Berg MP, Cornelissen JHC (2010) Turning northern peatlands upside down: Disentangling microclimate and substrate quality effects on vertical distribution of Collembola. Functional Ecology, 24, 1362-1369.

Kraft NJB, Adler PB, Godoy O, James EC, Fuller S, Levine JM (2015) Community assembly, coexistence and the environmental filtering metaphor. Functional Ecology, 29, 592-599.

Lavelle P, Decaëns T, Aubert M, Barot S, Blouin M, Bureau F, Margerie P, Mora P, Rossi JP (2006) Soil invertebrates and ecosystem services. European Journal of Soil Biology, 42, S3-S15.

Lavelle P, Spain AV (2001) Soil Ecology. Kluwer Academic Publishers, Dordrecht.

Legendre P (1993) Spatial autocorrelation: Trouble or new paradigm? Ecology, 74, 1659-1673.

Leibold MA, Holyoak M, Mouquet N, Amarasekare P, Chase JM, Hoopes MF, Holt RD, Shurin JB, Law R, Tilman D, Loreau M, Gonzalez A (2004) The metacommunity concept: A framework for multi-scale community ecology. Ecology Letters, 7, 601-613.

Levin SA (1992) The problem of patterns and scale in ecology: The Robert H. MacArthur Award lecture. Ecology, 73, 1943-1967.

Levine JM, HilleRisLambers J (2009) The importance of niches for the maintenance of species diversity. Nature, 461, 254-257.

Liang WJ, Jiang Y, Li Q (2006) Spatial distribution characteristics of plant-parasitic nematodes in cultivated horizon of a site-specific experimental field. Acta Ecologica Sinica, 26, 33-39. (in Chinese with English abstract) [梁文举, 姜勇, 李琪 (2006) 定位试验地耕层土壤植物寄生线虫空间分 布特征. 生态学报, 26, 33-39.]

Liang WJ, Jiang Y, Li Q, Liu YJ, Wen DZ (2005) Spatial distribution of bacterivorous nematodes in a Chinese Ecosystem Research Network (CERN) site. Ecological Research, 20, 481-486. 
Lin L, Gao MX, Wu DH, Zhang XP, Wu HT (2014) Co-occurrence patterns of above-ground and below-ground mite communities in farmland of Sanjiang Plain, Northeast China. Chinese Geographical Science, 24, 339-347.

Lindo Z, Winchester NN (2009) Spatial and environmental factors contributing to patterns in arboreal and terrestrial oribatid mite diversity across spatial scales. Oecologia, 160, 817-825.

Liu J, Gao MX, Wu DH (2017) Characteristics of grounddwelling soil macro-arthropod communities in a biodiversity monitoring plot of black soil cropland, northeastern China. Chinese Journal of Applied Ecology, 28, 3965-3975. (in Chinese with English abstract) [刘洁, 高梅香, 吴东辉 (2017) 基于黑土农田生物多样性监测样地的地表大型节 肢动物群落特征. 应用生态学报, 28, 3965-3975.]

Logue JB, Mouquet N, Peter H, Hillebrand H, The Metacommunity Working Group (2011) Empirical approaches to metacommunities: A review and comparison with theory. Trends in Ecology \& Evolution, 26, 482-491.

Loranger G, Ponge JF, Blanchart E, Lavelle P (1998) Impact of earthworms on the diversity of microarthropods in a vertisol (Martinique). Biology and Fertility of Soils, 27, 21-26.

Lundholm JT (2009) Plant species diversity and environmental heterogeneity: Spatial scale and competing hypotheses. Journal of Vegetation Science, 20, 377-391.

MacArthur RH, Wilson EO (1967) The Theory of Island Biogeography. Princeton University Press, Princeton.

Maraun M, Alphei J, Bonkowski M, Buryn R, Migge S, Peter M, Schaefer M, Scheu S (1999) Middens of the earthworm Lumbricus terrestris (Lumbricidae): Microhabitats for micro- and mesofauna in forest soil. Pedobiologia, 43, 276-287.

Maraun M, Erdmann G, Fischer BM, Pollierer MM, Norton RA, Schneider K, Scheu S (2011) Stable isotopes revisited: Their use and limits for oribatid mite trophic ecology. Soil Biology \& Biochemistry, 43, 877-882.

Maraun M, Schatz H, Scheu S (2007) Awesome or ordinary? Global diversity patterns of oribatid mites. Ecography, 30, 209-216.

Maraun M, Scheu S (2010) The structure of oribatid mite communities (Acari, Oribatida): Patterns, mechanisms and implications for future research. Ecography, 23, 374-382.

Margerie P, Decaëns T, Bureau F, Alard D (2001) Spatial distribution of earthworm species assemblages in a chalky slope of the Seine Valley (Normandy, France). European Journal of Soil Biology, 37, 291-296.

Mayfield MM, Levine JM (2010) Opposing effects of competitive exclusion on the phylogenetic structure of communities. Ecology Letters, 13, 1085-1093.

Mclean MA, Parkinson D (2000) Introduction of the epigeic earthworm Dendrobaena octaedra changes the oribatid community and microarthropod abundances in a pine forest. Soil Biology \& Biochemistry, 32, 1671-1681.

Migge S (2001) The Effect of Earthworm Invasion on Nutrient
Turnover, Microorganisms and Microarthropods in Canadian Aspen Forest Soil. PhD dissertation, Cuvillier Verlag, Göttingen.

Mitchell EAD, Borcard D, Buttler A, Grosvernier Ph, Gobat JM (2000) Horizontal distribution patterns of Testate Amoebae (Protozoa) in a Sphagnum magellanicum Carpet. Microbial Ecology, 39, 290-300.

Miyashita T, Niwa S (2006) A test for top-down cascade in a detritus-based food web by litter-dwelling web spiders. Ecological Research, 21, 611-615.

Moore PD (2002) Springboards for springtails. Nature, 418, 381.

Morrien E, Hannula SE, Snoek LB, Helmsing NR, Zweers H, Hollander M, Soto RL, Bouffaud ML, Buee M, Dimmers W, Duyts H, Geisen S, Girlanda M, Griffiths RI, Jørgensen HB, Jensen J, Plassart P, Redecker D, Schmelz M, Schmidt O, Thomson BC, Tisserant E, Uroz S, Winding A, Bailey MJ, Bonkowski M, Faber JH, Martin F, Lemanceau P, Boer W, Veen JA, van der Putten WH (2017) Soil networks become more connected and take up more carbon as nature restoration progresses. Nature Communications, 8, 1-11.

Morrison LW (2002) Long-term impacts of an arthropod-community invasion by the imported fire ant, Solenopsis invicta. Ecology, 83, 2337-2345.

Mumladze L, Murvanidze M, Behan-Pelletier V (2013) Compositional patterns in Holarctic peat bog inhabiting oribatid mite (Acari: Oribatida) communities. Pedobiologia, 56, 4148.

Nathan R (2006) Long-distance dispersal of plants. Science, 313, 786-788.

Ni JP, Cheng SS, Gao MX, Lu TY, Jin GZ (2018b) Spatial heterogeneities of ground-dwelling Coleoptera adults and their spatial correlations with environmental factors in a typical broad-leaved Korean pine forest in the Fenglin Nature Reserve. Biodiversity Science, 26, 14-26. (in Chinese with English abstract) [倪娟平, 程赛赛, 高梅香, 卢廷玉, 金光泽 (2018b) 丰林典型阔叶红松林地表鞘翅目成虫空 间异质性及其与环境因子的空间关联性. 生物多样性, 26, 14-26.]

Ni JP, Cheng SS, Gao MX, Zhang C, Li JK (2018a) Diversity and interspecific associations of ground Coleoptera in a broad-leaved Korean pine mixed forest. Chinese Journal of Ecology, 37, 1417-1425. (in Chinese with English abstract) [倪娟平, 程赛赛, 高梅香, 张超, 李景科 (2018a) 阔叶 红松林地表鞘翅目多样性及种间关联性. 生态学杂志, 37, 1417-1425.]

Niu KC, Liu YN, Shen ZH, He FL, Fang JY (2009) Community assembly: The relative importance of neutral theory and niche theory. Biodiversity Science, 17, 579-593. (in Chinese with English abstract) [牛克昌, 刘怿宁, 沈泽吴, 何芳良, 方精云 (2009) 群落构建的中性理论和生态位 理论. 生物多样性, 17, 579-593.]

Oconnell T, Bolger T (1998) Intraspecific aggregation, “probability niches" and the diversity of soil microarthropod 
assemblages. Applied Soil Ecology, 9, 63-67.

Pace ML, Cole JJ, Carpenter SR, Kitchell JF (1999) Trophic cascades revealed in diverse ecosystems. Trends in Ecology \& Evolution, 14, 483-488.

Padial AA, Ceschin F, Declerck SAJ, Meester LD, Bonecker CC, Lansac-Toha FA, Rodrigues L, Rodrigues LC, Train S, Velho LFM, Bini LM (2014) Dispersal ability determines the role of environmental, spatial and temporal drivers of metacommunity structure. PLoS ONE, 9, e111227.

Peña EDL, Vandegehuchte ML, Moens M, Bonte D (2011) Nematodes surfing the waves: Long-distance dispersal of soil-borne microfauna via sea swept rhizomes. Oikos, 120, 1649-1656.

Perry JN, Winder L, Holland JM, Alston RD (1999) Red-blue plots for detecting clusters in count data. Ecology Letters, 2, 106-113.

Petersen H, Luxton MA (1982) A comparative analysis of soil fauna populations and their role in decomposition processes. Oikos, 39, 287-388.

Rantalainen ML, Fritze H, Haimi J, Pennanen T, Setälä H (2005) Species richness and food web structure of soil decomposer community as affected by the size of habitat fragment and habitat corridors. Global Change Biology, 11, 1614-1627.

Rantalainen ML, Haimi J, Setälä H (2004) Testing the usefulness of habitat corridors in mitigating the negative effects of fragmentation: The soil faunal community as a model system. Applied Soil Ecology, 25, 267-274.

Robertson GP (1987) Geostatistics in ecology: Interpolating with known variance. Ecology, 68, 744-748.

Robertson GP, Freckman DW (1995) The spatial distribution of nematode trophic groups across a cultivated ecosystem. Ecology, 76, 1425-1432.

Rossi JP (2003a) Clusters in earthworm spatial distribution. Pedobiologia, 47, 490-496.

Rossi JP (2003b) The spatiotemporal pattern of a tropical earthworm species assemblage and its relationship with soil structure. Pedobiologia, 47, 497-503.

Rossi JP, Lavellea P, Albrecht A (1997) Relationships between spatial pattern of the endogeic earthworm Polypheretima elongata and soil heterogeneity. Soil Biology \& Biochemistry, 29, 485-488.

Rossi JP, Quénéhervé P (1998) Relating species density to environmental variables in presence of spatial autocorrelation: A study case on soil nematodes distribution. Ecography, 21, 117-112.

Russell DJ, Griegel A (2006) Influence of variable inundation regimes on soil collembola. Pedobiologia, 50, 165-175.

Ryti RT (1991) Theoretical considerations of density-dependent spacing of a mound-building ant (Formica altipetens). Journal of Theoretical Biology, 147, 289-301.

Saetre P (1999) Spatial patterns of ground vegetation, soil microbial biomass and activity in a mixed spruce-birch stand. Ecography, 22, 183-192.
Saetrea P, Bååthb E (2000) Spatial variation and patterns of soil microbial community structure in a mixed spruce-birch stand. Soil Biology and Biochemistry, 32, 909-917.

Sala S, Marta C, Marco V (2010) Spatially explicit method for ecotoxicological risk assessment of pesticides for birds. Ecotoxicology and Environmental Safety, 73, 213-221.

Salmon S, Geoffroy JJ, Ponge JF (2005) Earthworms and collembola relationships: Effects of predatory centipedes and humus forms. Soil Biology \& Biochemistry, 37, 487-495.

Sanders NJ, Gotelli NJ, Heller NE, Gordon DM (2003) Community disassembly by an invasive species. Proceedings of the National Academy of Sciences, USA, 100, 2474-2477.

Schneider K, Migge S, Norton RA, Scheu S, Langel R, Reineking A, Maraun M (2004) Trophic niche differentiation in soil microarthropods (Oribatida, Acari): Evidence from stable isotope ratios $\left({ }^{15} \mathrm{~N} /{ }^{14} \mathrm{~N}\right)$. Soil Biology \& Biochemistry, 36, 1769-1774.

Schooley RL, Wiens JA (2003) Spatial patterns, density dependence, and demography in the harvester ant, Pogonomyrmex rugosus in semi-arid grasslands. Journal of Arid Environments, 53, 183-196.

Sha D, Gao MX, Sun X, Wu DH, Zhang XP (2015) Relative contributions of spatial and environmental processes and biotic interactions in a soil collembolan community. Chinese Geographical Science, 25, 582-590.

Shao YH, Zhang WX, Liu SJ, Wang XL, Fu SL (2015) Diversity and function of soil fauna. Acta Ecologica Sinica, 35, 6614-6625. (in Chinese with English abstract) [邵元虎, 张 卫信, 刘胜杰, 王晓丽, 傅声雷 (2015) 土壤动物多样性 及其生态功能. 生态学报, 35, 6614-6625.]

Shurin JB, Borer ET, Seabloom EW, Borer ET (2002) A cross-ecosystem comparison of the strength of trophic cascades. Ecology Letters, 5, 785-791.

Smith ADM, Wallace HR (1976) Fluctuations in the distribution and numbers of Helicotylenchus dihystera in Kikuyu turf (Pennisetum clandestinum). Nematologica, 22, 145-152.

Starzomski BM, Srivastava DS (2007) Landscape geometry determines community response to disturbance. Oikos, 116, 690-699.

Stein A, Gerstner K, Kreft H (2014) Environmental heterogeneity as a universal driver of species richness across taxa, biomes and spatial scales. Ecology Letters, 17, 866-880.

Takada MB, Miyashita T (2014) Dispersal-mediated effect of microhabitat availability and density dependence determine population dynamics of a forest floor web spider. Journal of Animal Ecology, 83, 1047-1056.

Tamme R, Hiiesalu I, Laanisto L, Szava-Kovats R, Partel M (2010) Environmental heterogeneity, species diversity and co-existence at different spatial scales. Journal of Vegetation Science, 21, 796-801.

Terauds A, Chown SL, Bergstrom DM (2011) Spatial scale and species identity influence the indigenous-alien diversity relationship in springtails. Ecology, 92, 1436-1447.

Thakur MP, Wright AJ (2017) Environmental filtering, niche 
construction, and trait variability: The missing discussion. Trends in Ecology and Evolution, 32, 884-886.

Thomas RS, Harwood JD, Glen DM, Symondson WOC (2009) Tracking predator density dependence and subterranean predation by carabid larvae on slugs using monoclonal antibodies. Ecological Entomology, 34, 569-579.

Tilman D, Kareiva PM (1997) Spatial Ecology, The Role of Space in Population Dynamics and Interspecific Interactions. Princeton University Press, New Jersey.

Tiunov AV (2007) Stable isotopes of carbon and nitrogen in soil ecological studies. Biology Bulletin, 34, 395-407.

Tiunov AV, Kuznetsova NA (2000) Environmental activity of anecic earthworms (Lumbricus terrestris L.) and spatial organization of soil communities. Izvestiya Akademii Nauk Seriya Biologicheskaya, (5), 607-616.

Tobler W (1970) A computer movie simulating urban growth in the detroit region. Economic Geography, 46, 234-240.

Traniello JFA, Levings SC (1986) Intra- and intercolony patterns of nest dispersion in the ant Lasius neoniger: Correlations with territoriality and foraging ecology. Oecologia, 69, 413-419.

Ulrich W, Fiera C (2009) Environmental correlates of species richness of European springtails (Hexapoda: Collembola). Acta Oecologica, 35, 45-52.

Vellend M (2016) The Theory of Ecological Communities. Princeton University Press, New Jersey.

Violle C, Navas ML, Vile D, Kazakou E, Fortunel C, Hummel I, Garnier E (2007) Let the concept of trait be functional! Oikos, 116, 882-892.

Wackett AA, Yoo K, Olofsson J, Klaminder J (2018) Human-mediated introduction of geoengineering earthworms in the Fennoscandian arctic. Biological Invasions, 20, 13771386.

Walker KL (2006) Impact of the little fire ant, Wasmannia auropunctata, on native forest ants in Gabon. Biotropica, 38, 666-673.

Wang T, Ren SY, Yuan ZL, Zhu Y, Pan N, Li LX, Ye YZ (2014) Effects of density dependence on the spatial patterns of Quercus aliena var. acuteserrata trees in deciduous broad-leaved forest in the Baotianman Nature Reserve, central China. Biodiversity Science, 22, 449-457. (in Chinese with English abstract) [王婷, 任思远, 袁志良, 祝燕, 潘 娜, 李鹿金金, 叶永忠 (2014) 密度制约对宝天曼落叶阔叶 林锐齿柇死亡前后分布格局的影响. 生物多样性, 22, 449-457.]

Wardle DA (2002) Communities and Ecosystems: Linking the Aboveground and Belowground Components. Princeton University Press, New Jersey.

Wardle DA (2006) The influence of biotic interactions on soil biodiversity. Ecology Letters, 9, 870-886.

Wardle DA, Williamson WM, Yeates GW, Bonner KI (2005) Trickle-down effects of aboveground trophic cascades on the soil food web. Oikos, 111, 348-358.

Webster R, Boag B (1992) Geostatistical analysis of cyst nematodes in soil. European Journal of Soil Science, 43, 583-595.

Whittaker RJ, Heegaard E (2003) What is the observed relationship between species richness and productivity? Ecology, 84, 3390-3395.

Wickenbrock L, Heisler C (1997) Influence of earthworm activity on the abundance of collembola in soil. Soil Biology \& Biochemistry, 29, 517-521.

Wiensr JA, Milne BT (1989) Scaling of “landscapes” in landscape ecology, or, landscape ecology from a beetle's perspective. Landscape Ecology, 3, 87-96.

Wilson EO (1961) The nature of the taxon cycle in the melanesian ant fauna. The American Naturalist, 95, 169-193.

Zaitsev AS, Straalen NMV, Berg MP (2013) Landscape geological age explains large scale spatial trends in oribatid mite diversity. Landscape Ecology, 28, 285-296.

Zaitsev AS, Wolters V, Waldhardt R, Dauber J (2006) Long-term succession of oribatid mites after conversion of croplands to grasslands. Applied Soil Ecology, 34, 230-239.

Zhang LM, Gao MX, Liu D, Zhang XP, Wu DH (2016) Relative contributions of environmental filtering and dispersal limitation in species co-occurrence of above- and below-ground soil mite communities. Acta Ecologica Sinica, 36, 3951-3959. (in Chinese with English abstract) [张丽梅, 高梅香, 刘冬, 张雪萍, 吴东辉 (2016) 环境篮选和扩散 限制在地表和地下螨群落物种共存中的调控作用. 生态 学报, 36, 3951-3959.]

Zhao C, Griffin JN, Wu XW, Sun SC (2013) Predatory beetles facilitate plant growth by driving earthworms to lower soil layers. Journal of Animal Ecology, 82, 749-758.

Zhu JY, Li JK, Gao MX, Hu YY, Zhang XP (2017) Spatially heterogeneous dynamics of adult Coleoptera communities at a small scale in a Pinus koraiensis plantation on Maoer Mountain. Acta Ecologica Sinica, 37, 1-12. (in Chinese with English abstract) [朱纪元, 李景科, 高梅香, 胡媛媛, 张雪 萍 (2017) 帽儿山红松人工林鞘翅目成虫群落小尺度空 间异质性变化特征. 生态学报, 37, 1-12.]

Zhu Y, Mi XC, Ma KP (2009) A mechanism of plant species coexistence: The negative density-dependent hypothesis. Biodiversity Science, 17, 594-604. (in Chinese with English abstract) [祝燕, 米湘成, 马克平 (2009) 植物群落物种共 存机制: 负密度制约假说. 生物多样性, 17, 594-604.]

(责任编委：傅声雷 责任编辑：时意专) 